\title{
Dubleks Paslanmaz Çeliklerde Sigma Fazının Korozyon Dayanımına Etkileri
}

\author{
Aziz Barış BAŞYİĞİT ve Adem KURT \\ MKEK Mühimmat Fabrikası, Sanayi ve Teknoloji Müdürlüğü \\ Gazi Üniversitesi, Teknoloji Fakültesi, Metalurji ve Malzeme Mühendisliği Bölümü \\ Telefon:+905336120521 abbasyigit@gazi.edu.tr, ademkurt@gazi.edu.tr
}

\begin{abstract}
Duplex stainless steels consistsof approximately half austenitic and half $\delta$-ferritic phases and are preferred due to applications demanding both satisfactory corrosion and strength properties versus solely ferritic and austenitic grades. In this work; deleterious sigma phase that may form in microstructures of $\mathbf{S 3 2 2 0 5}$ (2205) duplex stainless steel plates was intended to be quantified after various thermal conditions such as heat treatments, welding and service life and also the effects of sigma phase on microstructural and corrosion properties were investigated. Sigma phase was formed in two distinct raw material by applying heat treatments, and microstructural and corrosion states were analyzed. For this purpose; $800^{\circ} \mathrm{C}$ was adjusted as heat treatment temperature and two seperate specimens were heated through 5,5 and 16 hours of duration time in consequenceof the most rapidly formation rate of sigma phase at this temperature.
\end{abstract}

Index Terms-Duplex Stainless Steels, Sigma Phase, Corrosion in Stainless Steels.

Özet-Dubleks paslanmaz çelikler; delta-ferrit ve östenit fazlarının yaklaşık olarak yarı-yarıya bir arada bulunduğu ve ferritik ile östenitik türlere göre yeterli korozyon dayanımı ve mukavemet özelliklerinin bir arada istendiği uygulamalarda tercih edilmektedir.

Bu çalışmada; dubleks paslanmaz çeliklerde ısıl işlem ve kaynakuygulaması veya kullanım ömrü süresince değişen termal koşullara göre mikro yapıda oluşabilecek zararlı fazlardan olan sigma fazının tespit edilmesi ve korozyon davranışlarına etkilerinin incelenmesi amaçlanmıştır. Sigma fazı iki ayrı ana malzemede ısıl işlem ile oluşturulmuş, mikro yapısal ve korozyon davranış durumları incelenmiştir. Bu amaçla; sigma fazının en hızlı oluştuğu $800^{\circ} \mathrm{C}$ sıcaklığı ısıl işlem amacıyla seçilmiş ve iki ayrı numuneye 5,5 saat ve 16 saat sürelerle ısıl işlem uygulanmıştır. Bu sıcaklıkta bekleme süresinin sigma fazının miktarına ve korozyon dayanımına etkileri de araştırılmıştır.

Anahtar kelimeler - Dubleks Paslanmaz Çelik, SigmaFazı, Paslanmaz Çeliklerde Korozyon.

\section{GíRIŞ}

$\mathrm{D}$ ubleks paslanmaz çelikler; üstün korozyon dirençleri, mukavemetleri veya her iki avantajlarından faydalanılan uygulamalarda kullanılmaktadırlar. Ayrıca çoğu korozif uygulamalarda yapı çeliklerine göre üstündürler ve kıyaslanabilir mukavemete sahiptirler. Dubleks paslanmaz çelikler hem sahilde hem de kıyıdan uzakta petrol ve gaz boru hatlarında yaygın bir şekilde kullanılmaktadırlar $[1,2]$.
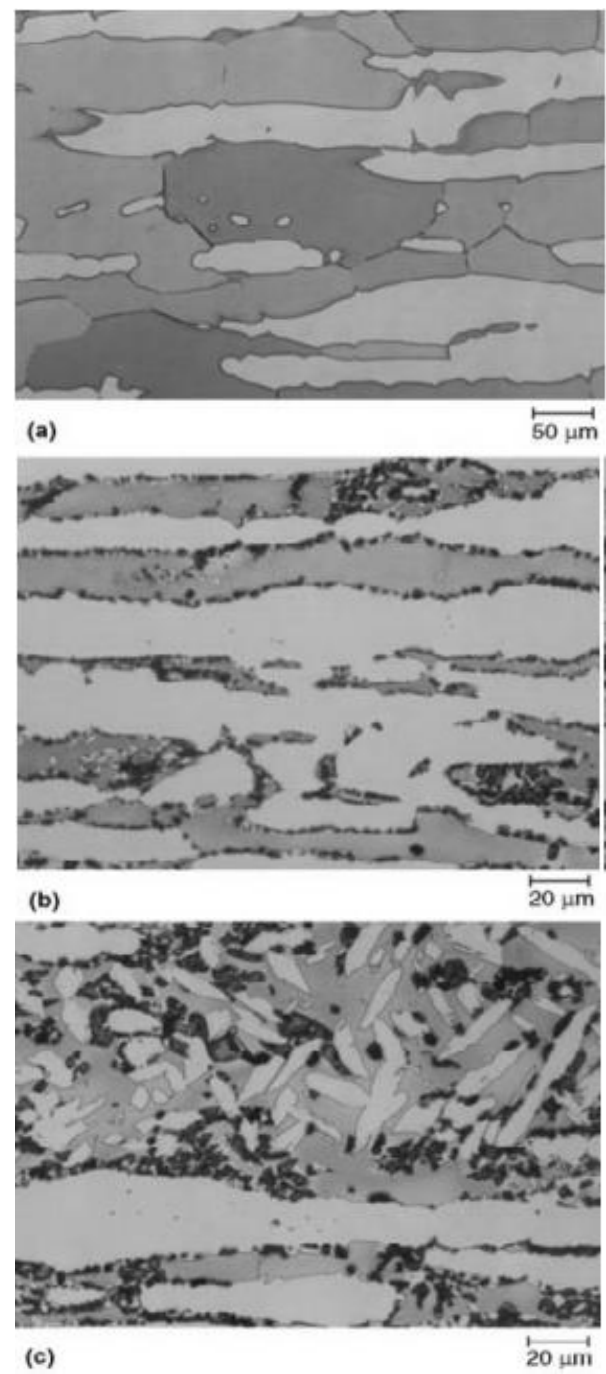

Şekil 1. 2205 dubleks paslanmaz çelikte sigma fazı oluşumu, $\% 20 \mathrm{NaOH}$ [3]

Dubleks paslanmaz çelikler, düşük sıcaklıklarda bazı kırılganlaştırıcı çökeltiler oluşturduklarından dolayı yaklaşık 
olarak $280^{\circ} \mathrm{C}$ sicaklığg geçen kullanım uygulamalarında tavsiye edilmemektedirler. Dubleks paslanmaz çeliklerin kullanım sıcaklığ sınırlıdır. $\mathrm{Bu}$ zararlı çökeltilerin içerisinde en önemlisi tetragonal yapıda bir Fe- Ni-Cr-Mo bileşiği olan sigma $(\sigma)$ fazıdır. Sigma fazı esasen bütün paslanmaz çeliklerde meydana gelebilmekte ancak daha çok yüksek krom (>\%20 ağırlıça) içeriğine sahip olan östenitik, ferritik ve dubleks alaşımlarda oluşmaktadır [1].

Sigma fazı ve diğer metaller-arası bileşiklerin oluşumu yaklaşık olarak $570^{\circ} \mathrm{C}$ sicaklıkta başlamakta ve en hızlı $800^{\circ} \mathrm{C}$ ile $850^{\circ} \mathrm{C}$ aralığında gerçekleşmektedir. Alaşımın bileşimine bağlı olarak bu bileşikler $1000^{\circ} \mathrm{C}$ sicaklığın üzerinde tekrar çözünmektedirler. Bununla birlikte; \%25 civarı $\mathrm{Cr}$ içeren dubleks paslanmaz çeliklerde metaller-arası fazların oluşumu çok daha hızlıdır. Sigma fazının oluşumundan kaçınmak için yaklaşıkolarak $900^{\circ} \mathrm{C}$ ' den $500^{\circ} \mathrm{C}$ sicaklık aralığını hızlı geçiş gerekmektedir. Krom içeriği \%20 değerinin altında olan alaşımlarda sigma fazının oluşması için uzun süreler gereklidir [1].

Şekil 1' de 2205 dubleks paslanmaz çelikte sigma fazı oluşumu görülmektedir [3]. Şekil 1-(a)' da $1200^{\circ} C^{\prime}$ de çözelti tavlanmış delta-ferrit ve östenitten oluşan yapı Şekil 1-(b)'de $800^{\circ} \mathrm{C}$ 'de 2 saat tutulmuş ve Şekil 1 -(c)'de yine $800^{\circ} \mathrm{C}$ 'de 8 saat tutulmuş yapıdaki sigma fazı (koyu kahverengi) görülmekte açık renkli faz östeniti açık kahve faz delta ferriti temsil etmektedir.

Sigma fazının en hızlı ve yoğun oluştuğu $800^{\circ} \mathrm{C}$ sıcaklıkta artan bekleme süresi bu fazın miktarını artırmaktadır $[1,2,3,4]$.

Fe-Cr-Ni alaşımlarında, \%5 değerinden daha az bir sigma fazı içeriğinin, darbe enerjisini \%50'den fazla azaltabileceği Şekil 2'de; ifade edilmektedir [1].

Ayrıca; krom ve molibdence zengin kırılgan yapıda olan olan sigma fazı, paslanmaz çeliklerin darbe enerjilerini düşürmekle beraber korozyon dayanımını da azaltmaktadır [2].

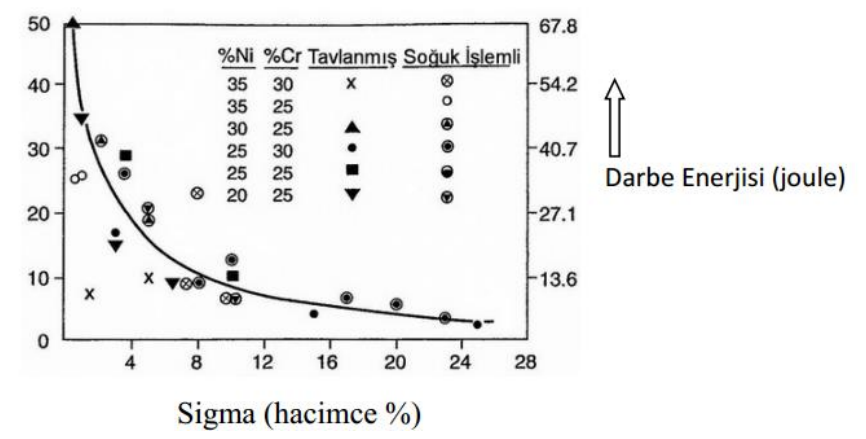

Şekil 2. Sigma faz içeriğinin darbe enerjisine etkileri [1]

\section{DENEYSEL ÇALIŞMALAR}

Deneysel çalışmalarda, 3×25x50mm ebatlarında S32205 (2205) dubleks paslanmaz çelik saclar hazırlanmıştır. S32205 dubleks paslanmaz çeliğin kimyasal bileşimi Tablo 1' de verilmektedir.

Tablo I.

S322205 dubleks paslanmaz çeliğin kimyasal bileşimi

\begin{tabular}{llllll}
\hline \hline & \multicolumn{5}{l}{ Element (\%ă̆ırlık) } \\
$\mathrm{C}$ & $\mathrm{Mn}$ & $\mathrm{P}$ & $\mathrm{S}$ & $\mathrm{Si}$ & $\mathrm{Cr}$ \\
0,031 & 0,832 & 0,024 & 0,004 & 0,423 & 24,957 \\
$\mathrm{Ni}$ & $\mathrm{Mo}$ & $\mathrm{Fe}$ & $\mathrm{N}$ & $\mathrm{Cu}$ & Diğer \\
6,638 & 3,511 & 62,10 & 0,306 & 0,2152 & 0,9588 \\
\hline \hline
\end{tabular}

\section{A.Isıl işlemle sigma fazının oluşturulması}

$\mathrm{Bu}$ çalışmada; sigma fazının en hızlı ve yoğun oluştuğu $800^{\circ} \mathrm{C}$ sabit sicaklikta S32205 dubleks paslanmaz çelik numunelere 5.5 saat ve 16 saat süreyle 1 sıl işlem uygulanmıştır. Homojen 1sıl işlem uygulaması amacıyla 1sıl işlem süresince sıcaklığın sürekli sabit tutulduğu gözlenmiştir.

\section{B.Mikroyapısal incelemeler}

Mikroyapısal incelemeler için, 'Dubleks paslanmaz çeliklerde zararlı metaller-arası fazların tespiti' başlıklı ASTM A923 [5] standardından faydalanılmıştır. Numuneler; $\% 40 \mathrm{NaOH}$ içeriğine sahip çözeltide elektrolitik dağlama sonrası optik metalurji mikroskobunda $500 \mathrm{X}$ büyütmeye kadar incelenmiştir. Bununla birlikte fazların hacimce miktarsal analizleri için metalurji mikroskobunda 'Kameram' ve 'Metalim' yazılımları yardımıyla 'Faz (görüntü) analizleri uygulanmıştır.

\section{C.Korozyon Testi}

ASTM A923 standardına göre 2205 dubleks paslanmaz çelik saclarakorozyon (ağırlık kaybı) testi uygulanmıştır.

Ana malzemede ve iki farklı koşullarda uygulanan 1sıl işlemler sonrasında korozyon test numuneleri ASTM A923 standardına göre temizlenerek bütün ebatları ölçülmüş toplam yüzey alanı hesaplanmış ve her numune test öncesi $0,001 \mathrm{~g}$ hassasiyetinde terazide tartılarak ağırlığı tespit edilmiştir. $\mathrm{FeCl3} . \mathrm{H} 2 \mathrm{O}+$ saf su karışımı korozyon test çözeltisi PH derecesi 1.3 olacak şekilde hazırlanmış ve numuneler 24 saat süreyle laboratuarda $22^{\circ} \mathrm{C}$ sicaklıkta bu çözeltide bekletilmiş, oluşan korozyon ürünleri temizlendikten sonra tekrar terazide tartılmışlardır.

Korozyon test numunelerinin cam kap içerisinde bekletilirken örnek görüntüleri Şekil 3'de verilmektedir.

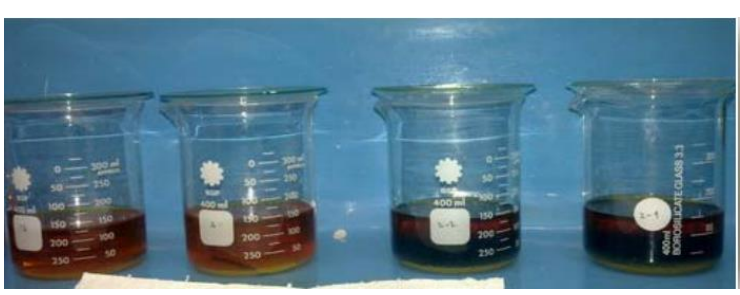

(a) (b)
Şekil 3. (a) Korozyon testinin yapılışı (b) test numunesi

\section{Korozyon deney sonuçlarının analitik hesaplanması}

ASTM A923 standardında korozyon miktarı (mdd) tespiti için ağırlık kaybına göre hesaplama yapılan eşitlik (Bkz. Eş 1.) kullanılmaktadır. 
Korozyon hızı $(\mathrm{mdd})=$ Ağırlık Kaybı $(\mathrm{mg}) /$ numune toplam yüzey alan1 (dm2) x zaman (gün) (Eş.1)

Test numunelerinin hesaplanmış olan toplam yüzey alanları, testöncesi ve test sonrası ağırlık ölçümleri farkı (ağırlık kaybı) ile birlikte test süresi 1 gün esas alınarak Eşitlik 4.2' de yerine koyulmakta ve her test numunesi için ayrı hesap yapılmaktadır.

Hesaplama sonrası çıkan değerler ASTM A923'e göre 10 mdd değerinden yüksek ise malzemede risk oluşturabilecek düzeyde zararlı metaller-arası faz veya bileşiklerin olabileceği ifade edilmektedir. Bulunan sonuç 10 mdd değerinin altında ise testin bir kez daha tekrarına izin verilmektedir.

\section{DENEYSEL SONUÇLAR}

A. Mikroyapisal incelemeler ve faz analizleri

2205 dubleks paslanmaz çelik ana malzemenin temin edilmiş haliyle mikroyapı görüntüleri Şekil 4' de verilmektedir.

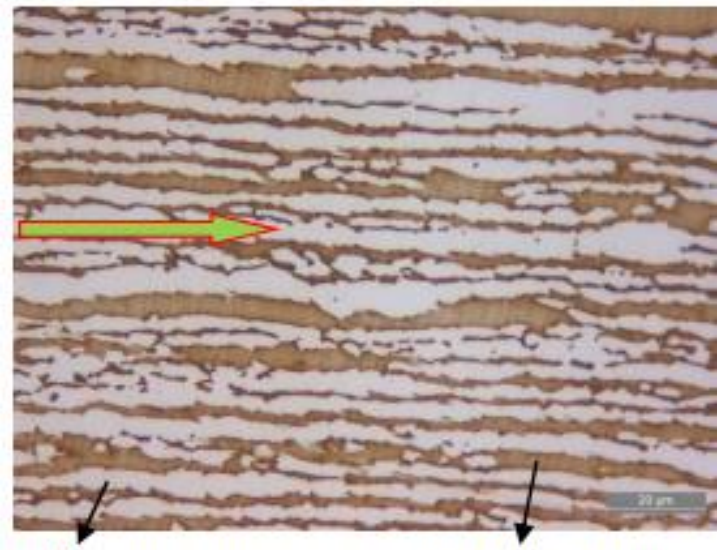

\section{(a)Östenit (beyaz) $\delta$-ferrit (kahverengi)}

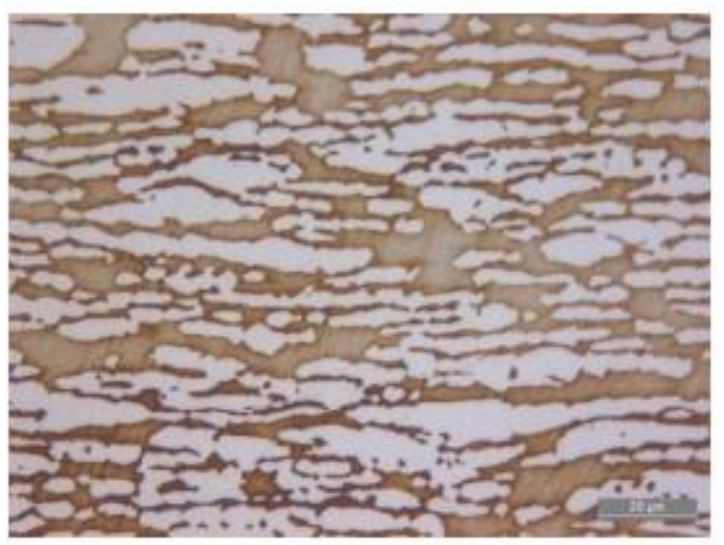

(b)

Şekil 4. İşlem görmemiş ana malzeme (a) boyuna (b) enine hadde yapısı (500X)

Şekil 4-(a) ve (b)' de dubleks paslanmaz çeliğin hadde yönü görülmektedir. Mikroyapısal incelemelerde; işlem görmemiş ana malzemede başka bir faza veya metallerarası bileşiğe rastlanmamıştır.

ASTM E562 [6] ve ASTME1245 [7] standartlarına göre uygulanan faz (görüntü) analizi sonucunda temin edilmiş haliyle S32205 dubleks paslanmaz çelik ana malzemede, ortalama \%54,08 $\delta$-ferrit ve $\% 45,92$ östenit fazlarına sahip olduğu bulunmuştur

Ana malzemenin 100x büyütme kapasitesinde uygulanan metalografik faz analiz sonucu Şekil 5' de görülmektedir. Faz analizi sonucunda Şekil 5'de görülen ana malzemedeki yeşil faz östeniti sarı faz ise delta ferriti temsil etmektedir.

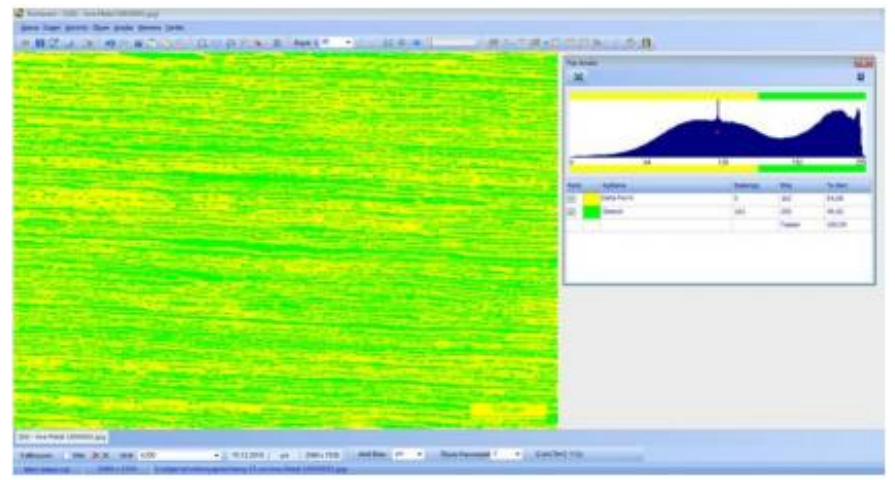

Şekil 5. Ana malzeme faz analizsonucu (\%54,08 $\delta$-ferrit ve \%45,92 östenit)

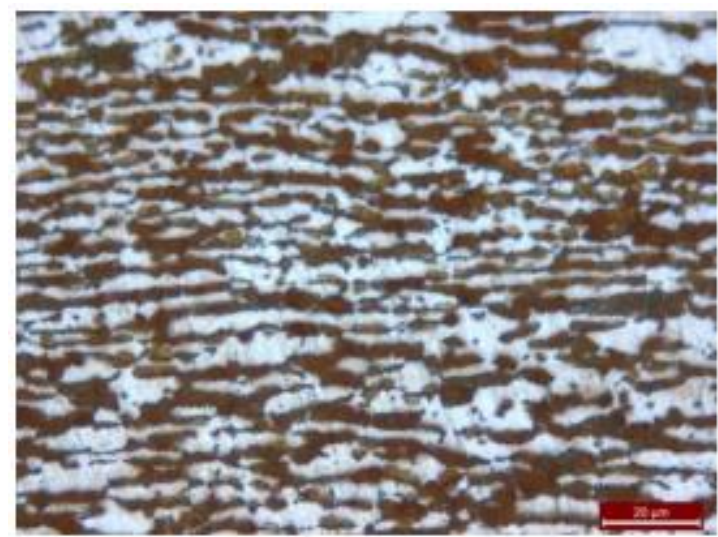

(a)

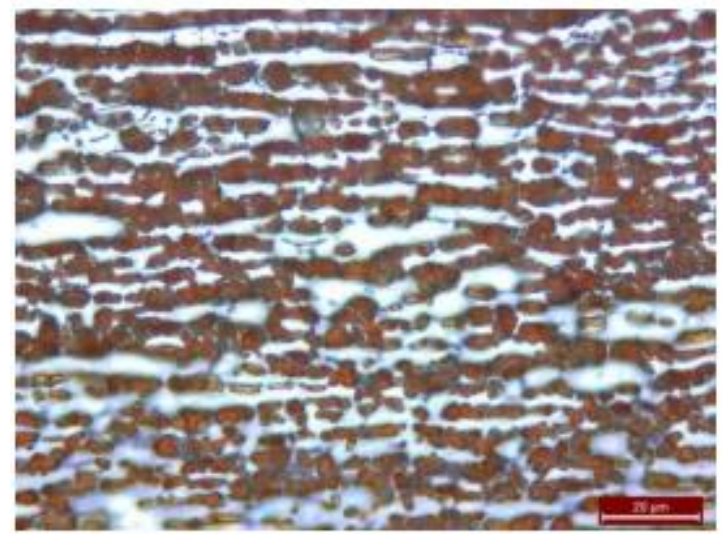

(b)

Şekil 6. Isıl işlem uygulanmış ana malzeme numunelerinin mikro yapı görüntüleri (beyaz: östenit, açık kahve: delta-ferrit, koyu kahve: sigma fazı, 500x) (a) $800^{\circ} \mathrm{C}$ 'de 5.5 h.bekleme ve soğutma, (b) $800^{\circ} \mathrm{C}$ 'de 16 h.bekleme ve soğutma.

Uygulanan iki farklı 1sıl işlemler sonrasında numunelerde oluşan sigma fazı mikroyapı görüntüleri Şekil 6'da gösterilmiştir. 
Şekil 6'da görüldüğü gibi, yapıda açık renkli (beyaz) olanlar östenit, açık kahve renkli olanlar delta ferrit ve koyu kahve renkli yapılar ise sigma fazını göstermektedir. Artan ısıl işlem süresi ile, oluşan sigma fazının boyutlarının da arttığı görülmektedir. Araştırmacılar yaptıkları çalışmalarda sigma fazının $570^{\circ} \mathrm{C}-1000^{\circ} \mathrm{C}$ aralığında oluştuğunu ve bu oluşumun en hızl $800^{\circ} \mathrm{C}-850^{\circ} \mathrm{C}$ ' de meydana geldiğini belirtmişlerdir [1].

Çalışmada, Şekil 7 ve Şekil 8'de sırasıyla iki ana malzemeye uygulanan $800^{\circ} \mathrm{C}$ sicaklıkta 5.5 ve 16 saat bekletilmesi sonrasında numunelerin faz analiz sonuçları gösterilmektedir.

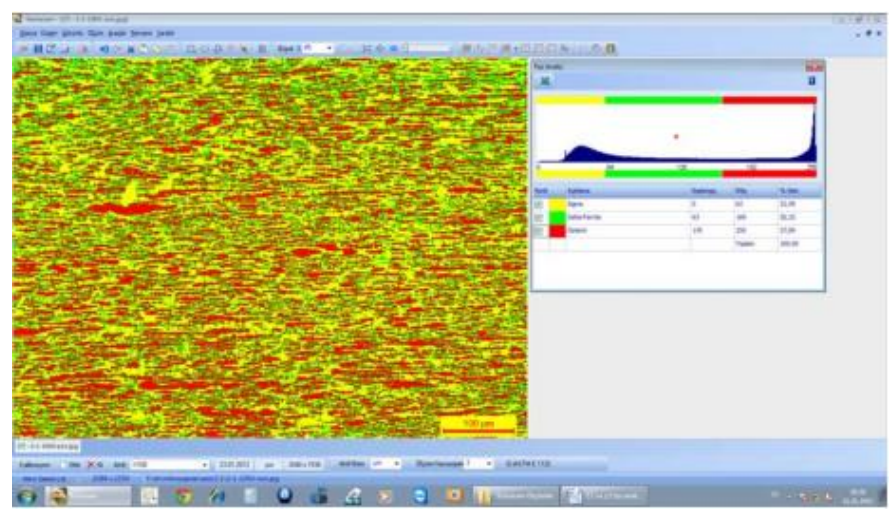

Şekil 7. $800^{\circ} \mathrm{C}$ 'de 5,5 saat bekletilen ve soğutulan ana malzemenumunesinin faz analizi sonucu (kırmızı: östenit: $\% 37.09$, yeşil: delta ferrit: $\% 30.32$, sarı: sigma: \%32.59)

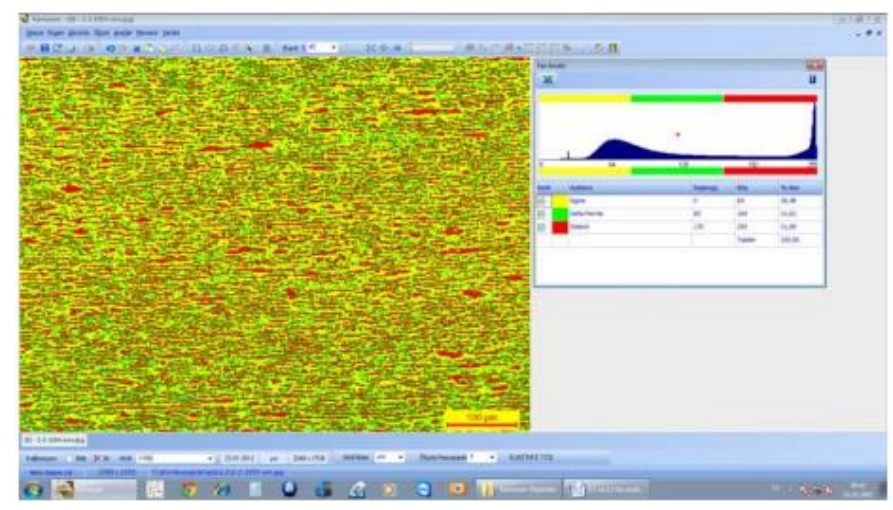

Şekil 8. $800^{\circ} \mathrm{C}$ sicaklıkta 16 saat bekletilen ve soğutulan ana malzeme numunesinin faz analizi sonucu (kırmızı: östenit: \%31,89, yeşil:delta ferrit: $\% 31,62$, sar1: sigma: \%36,48)

Şekil 7 ve Şekil 8' de görüldüğ̈̈ gibi, iki ayrı ana malzemeye uygulanan $800^{\circ} \mathrm{C}$ sicaklıkta 5,5 saat bekleme ve soğutma 1 sil işlemi sonucunda elde edilen numuneye yapılan faz analizinde $\% 32,59$ sigma fazı tespit edilirken, $800^{\circ} \mathrm{C}^{\prime}$ de 16 saat bekleme vesoğutma 1sıl işlemi uygulanan numunede ise \%36,48 sigma fazı tespit edilmiştir. Sigma fazının en hızlı oluştuğu $800^{\circ} \mathrm{C}$ sicaklıkta artan sürelerle bulunma sigma fazı oranını artırmıştır.

Ana malzeme ile birlikte iki farklı 1sıl işlem numunesinin faz analizleri sonuçları Tablo 2“ de görülmektedir.
Tablo II.

Faz analiz sonuçları

\begin{tabular}{|c|c|c|c|}
\hline \multirow[t]{2}{*}{ Numune } & \multicolumn{3}{|c|}{$\begin{array}{l}\text { ASTM E562 ve ASTM E1245 Faz (görüntü) } \\
\text { analiz sonucu (\% hacimce) }\end{array}$} \\
\hline & Östenit & $\delta$-ferrit & $\operatorname{sigma}(\sigma)$ \\
\hline Ana malzeme & 45,92 & 54,08 & --- \\
\hline $\begin{array}{l}800^{\circ} \mathrm{C}^{\prime} \mathrm{de} \quad 5,5 \text { saat } \\
\text { bekleme ve soğutma }\end{array}$ & 37,09 & 30,32 & 32,59 \\
\hline $\begin{array}{l}800^{\circ} \mathrm{C} \text { 'de } 16 \text { saat } \\
\text { bekleme ve soğutma }\end{array}$ & 31,89 & 31,62 & 36,48 \\
\hline
\end{tabular}

$800^{\circ} \mathrm{C}$ sıcaklıkta artan bekleme süresi sigma fazı miktarını artırmaktadır. Sigma fazı ferritten veya yarı-kararlı östenitten çekirdeklenmektedir. Ayrıca ferrit östenitten daha fazla krom içeriğine sahip olduğundan ferritin varlı̆ğ sigma fazı oluşumunu kolaylaştırmaktadır. Bundan dolayı; Tablo 2' deki sonuçlardan, artan sigma fazının delta-ferriti östenite göre daha çok tükettiği anlaşılmaktadır $[1,8]$.

\section{B. Korozyon Test Sonuçları}

ASTM A923 standardına göre uygulanan korozyon (ağırlık kaybı) test sonuçları aşağıda Tablo 3' de verilmektedir.

Ana malzeme korozyon testinden etkilenmemiştir. Korozyon testinde cam kap içerisindeki çözeltiye bırakılan numunelerin cam tabanına temas eden yüzeylerinde damlacıklar halinde bulunan korozif demir-klörür çözeltisi alt yüzeylerde çukurcuk korozyonuna sebep olmuştur.

Şekil 9' da, 1sıl işlemsiz ana malzemede herhangi bir korozyon durumu oluşmazken isıl işlemle sigma fazı oluşturulan numunelerde 1sıl işlem süresi arttıkça korozyon miktarının arttığı görülmektedir.

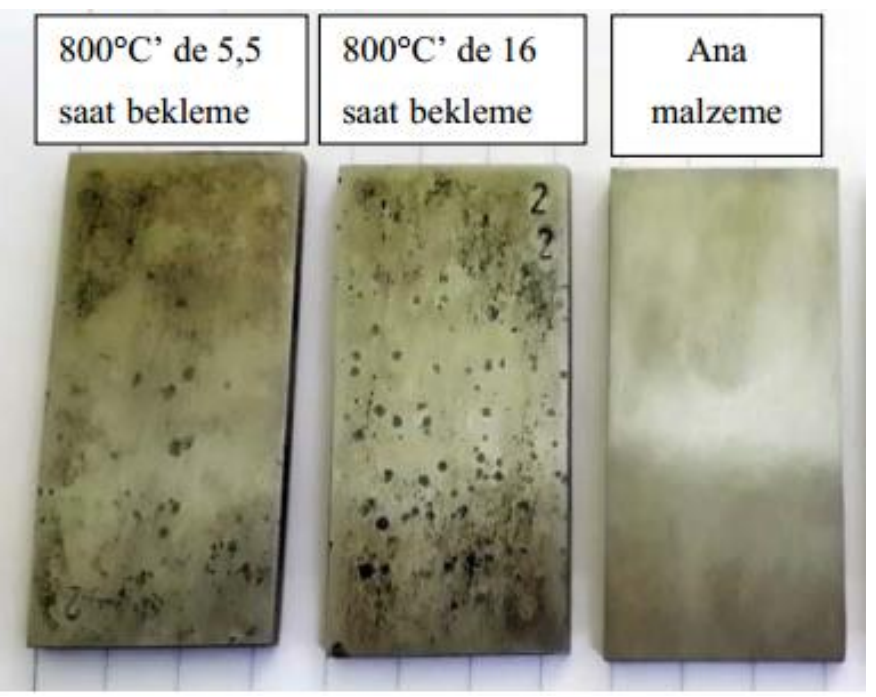

Şekil 9. $800^{\circ} \mathrm{C}^{\prime}$ de 5,5 ve 16 saat bekletilen ve soğutulan numunelerle, ana malzemenin korozyon testi sonrası yüzey durumları

Korozyon miktarı (1-Ana Malzeme): $(0,0000) \mathrm{g} /$ $0,27570752(\mathrm{dm} 2) \times 1$ (gün) $=0,0000$ mdd.

Korozyon miktarı (2.1): (0,3469) g / 0,27672510 (dm2) x 1 (gün) $=1253,6$ mdd .

Korozyon miktar1 (2.2): $(0,385) \mathrm{g} / 0,27575352(\mathrm{dm} 2) \times 1$ (gün) $=1396,17$ mdd. 
Tablo III. ASTM A923 Korozyon (ağırlık kaybı) test sonuçları

\begin{tabular}{|c|c|c|c|c|c|c|c|c|c|c|}
\hline $\begin{array}{l}\text { Numune } \\
\text { No }\end{array}$ & $\begin{array}{l}\text { Numune } \\
\text { Boyutları } \\
(\mathrm{mm})\end{array}$ & $\begin{array}{l}\text { Toplam } \\
\text { Yüzey } \\
\text { Alanları } \\
\left(\mathrm{dm}^{2}\right)\end{array}$ & $\begin{array}{l}\text { Test Öncesi } \\
\text { Ağırlık } \\
\text { 1.Tartım(g) }\end{array}$ & $\begin{array}{l}\text { Test Öncesi } \\
\text { Ağırlık } \\
\text { 2.Tartım(g) }\end{array}$ & $\begin{array}{l}\text { Test Öncesi } \\
\text { Ağırlık } \\
\text { 3.Tartım }(\mathrm{g})\end{array}$ & $\begin{array}{l}\text { Test } \\
\text { Öncesi } \\
\text { Ağırlık } \\
\text { Ortalama } \\
\text { (g) }\end{array}$ & $\begin{array}{l}\text { Test } \\
\text { Sonrası } \\
\text { Ağırlık } \\
\text { 1.Tartım } \\
\text { (g) }\end{array}$ & $\begin{array}{l}\text { Test } \\
\text { Sonrası } \\
\text { Ağırlık } \\
\text { 2.Tartım } \\
(\mathrm{g})\end{array}$ & $\begin{array}{l}\text { Test } \\
\text { Sonrası } \\
\text { Ağırlık } \\
\text { 3.Tartım } \\
\text { (g) }\end{array}$ & $\begin{array}{l}\text { Test } \\
\text { Sonrası } \\
\text { Ağırlık } \\
\text { Ortalama } \\
(\mathrm{g})\end{array}$ \\
\hline $\begin{array}{l}1 \quad \text { (ana } \\
\text { malzeme) }\end{array}$ & $\begin{array}{l}2,92 \times 23 \\
43 \times 49,72\end{array}$ & 0,27570752 & 25,6975 & 25,6977 & 25,6976 & 25,6976 & 25,6977 & 25,6976 & 25,6975 & 25,6976 \\
\hline $\begin{array}{ll}2.1 & (5,5 \\
\text { saat }) & \end{array}$ & $\begin{array}{l}2,95 \times 23 \\
50 \times 49,69\end{array}$ & 0,27672510 & 26,5029 & 26,5030 & 26,5030 & 26,5030 & 26,1561 & 26,1561 & 26,1560 & 26,1561 \\
\hline $\begin{array}{ll}2.2 & (16 \\
\text { saat }) & \end{array}$ & $\begin{array}{l}2,88 \times 23 \\
49 \times 49,72\end{array}$ & 0,27575352 & 25,4963 & 25,4963 & 25,4964 & 25,4963 & 25,1113 & 25,1113 & 25,1113 & 25,1113 \\
\hline
\end{tabular}

Östenit fazının klor içeren ortamlara karşı zayıflı̆̆ fazının ise bu klor içeren test ortamına östenite göre daha dayanıklı oluşu, korozyon test çözeltilerindeki klor iyonlarının östeniti daha fazla korozyona uğrattığı sonucunu ortaya çıkarmaktadır [1].

Şekil 10-(a) ve (b) ile Şekil $11^{\prime}$ de $800^{\circ} \mathrm{C}$ sicaklıkta sirasiyla 5,5 ve 16 saat bekletilen ve soğutulan numunelerde tespit edilen çukurcuk korozyon örnek şekilleri ve boyutları gösterilmektedir.

Şekil 10-(a) ve (b)' de görülen, $800^{\circ} \mathrm{C}$ sicaklıkta 5,5 saat bekletilmiş ve soğutulmuş numunede oluşan çukurcuk örneklerinden anlaşılacağı gibi; 1 ssıl işlem sonrası oluşan sigma fazı, demirklorür esaslı $(\mathrm{FeCl})$ korozyon testçözeltisine karşı tepki göstererek yukarıda Şekil 9' da Şekil 10' da verilen örnek makro-yapı fotoğraflarında gösterildiği gibi numuneyi tahrip etmiştir.

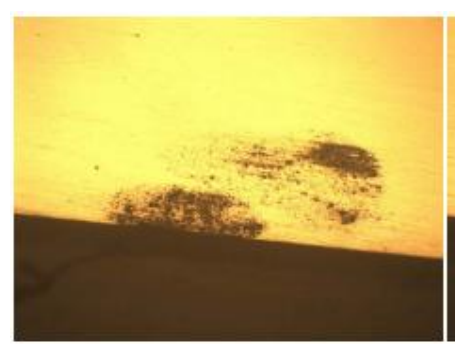

(a)

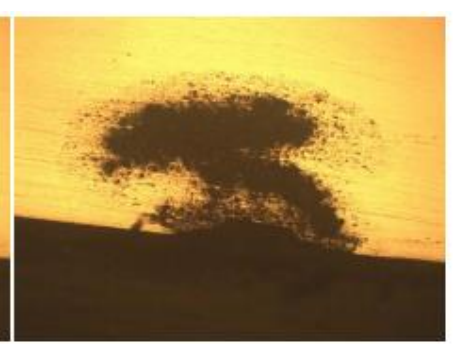

(b)
Şekil 10 -(a) ve (b) $800^{\circ} \mathrm{C}$ sıcaklıkta 5,5 saat bekletilmiş ve soğutulmuş numunede çukurcuk korozyonu örnek görüntüleri

$800^{\circ} \mathrm{C}$ sicaklıkta 16 saat bekletilmiş ve soğutulmuş numunede oluşan sigma fazının yol açtığı tahribat sonrasında meydana gelen çukurcuk boyutları Şekil 11' de gösterilmektedir.

Şekil 11' de, $800^{\circ} \mathrm{C}$ sicaklıkta 16 saat bekletilerek sigma fazı oluşturulan numunedeki çukurcuk korozyonu örneğinde, çukurcuk boyutları yaklaşık olarak $0,557 \mathrm{~mm}$ genişlikte ve 0,145 mm derinlikte tespit edilmiştir. Artan 1sıl işlem süresi sigma faz oranını ve yol açtığı korozif tahribatı artırmıştır

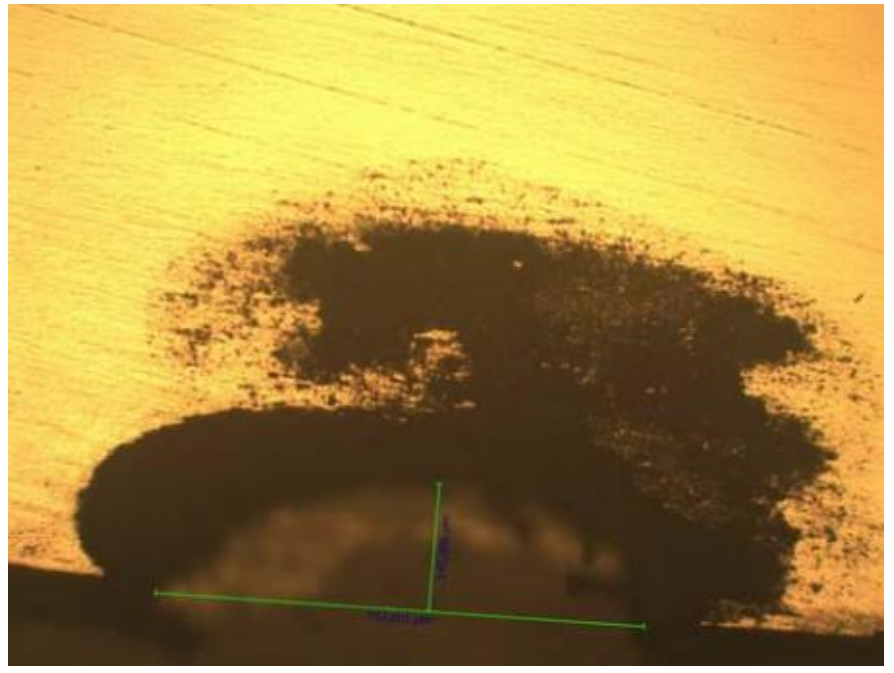

Şekil 11. $800^{\circ} \mathrm{C}$ 'de 16 saat bekletilen ana malzemede çukurcuk korozyonu görüntüsü (çukurcuk genişliği: 557,001 $\mu \mathrm{m}$, çukurcuk derinliği: $145,006 \mu \mathrm{m}$ )

\section{SONUÇLAR VE TARTIŞMA}

İşlem görmemiş S32205 dubleks paslanmaz çelik ana malzemede ASTM E562 ve ASTM E1245 standartlarına göre uygulanan mikroyapısal faz (görüntü) analizi sonucunda, ortalama $\% 54,08 \delta$-ferrit ve $\% 45,92$ östenit fazlar1 tespit edilmiştir.

İşlem görmemiş ana malzeme mikroyapıları ile birlikte, ana malzemeye iki farklı 1sıl işlem uygulayarak oluşturulan sigma fazının mikroyapıları literatürlebenzerlik göstermektedir $[1,2$, $3,4,9]$.

Ana malzemede sigma fazına rastlanmamış, $800^{\circ} \mathrm{C}$ sicaklıkta 5,5 ve 16 saat isıl işlem uygulanmış numunelerde, faz analizi sonucunda sirasiyla; hacimce $\% 32,59$ ve \%36,48 sigma fazı tespit edilmiştir. Bir Fe-Cr bileşiği olan sigma fazı dubleks paslanmaz çeliklerde en hızl $800^{\circ} \mathrm{C}$ sicaklıkta oluşabilmekte ve bu sicaklıkta artan bekleme süresi sigma fazı içeriğini artırmıştır.

Sigma fazı, tercihen kromun daha çok miktarda barındığı delta-ferrit fazından çekirdekleneceğinden dolayı numunelerin faz analiz sonuçlarına göre artan sigma fazı miktarı, delta ferritin içeriğini östenite göre daha fazla azaltmıştır $[1,2]$.

Bununla birlikte; bir $\mathrm{Fe}-\mathrm{Cr}$ bileşiği olan sigma fazının tercihen delta ferrit içerisinde çökelmesi nedeniyle delta ferrit içeriğinin dubleks paslanmaz çeliklerde östenitle olan denge 
bileşimini (\%50-\%55) geçmesi durumunda bir başka ifadeyle delta ferritin miktarının ana malzemenin denge oranlarını geçmesi durumunda sigma fazının delta ferrit içerisinde çökelme olasılığı artacak ve malzemenin korozyon ve mekanik dayanım özellikleri de o oranda azalacaktır.

Yapılan bir çalışmada; araştırmacılar, hidroklorik asit gibi indirgeyici ortamlarda sigma fazındaki korozyon miktarının delta-ferritten ortalama 3 kat fazla olduğunu, bunun yanında $\mathrm{H} 2 \mathrm{SO} 4 \mathrm{ve} \mathrm{HNO}$ gibi oksitleyici ortamlarda sigma fazının delta-ferrite göre 42 kata kadar daha fazla tahribata yol açtı̆̆ını ve buna karşın $\mathrm{FeCl} 3$ gibi çukurcuk korozyonu oluşturan ortamlarda ise delta-ferritin çözeltiden etkilenmediğini ancak sigma fazının tahribata yol açtığını vurgulamışlardır [10].

Ana malzeme korozyon testinden etkilenmemiştir. İşlem görmemiş ana malzemenin denge faz dağılımları optimum korozyon ve mekanik dayanım için çözeltiye alma ve su verme işlemleri sonucunda tertip edildiğinden korozyon dayanımında beklenen bu durum meydana gelmiştir.

Çalışmada iki farklı isıl işlemle ana malzemede oluşturulan sigma fazı korozyon testleri sonuçlarından da görüleceği üzere malzemede korozif tahribata yol açmıştır. Ayrıca artan sigma fazı içeriği korozyon dayanımını daha da düşürmüştür.

Dubleks paslanmaz çeliklerin üretimleri sonrasında mevcut olan tatminkar korozyon ve mekanik dayanımlarını koruyabilmek amacıyla yaklaşık olarak yarı yarıya delta ferritöstenit faz oran dağılımlarını kaynak, sıcak kullanım koşulları gibi termal prosesler sonrasında da muhafaza edebilmek için, sigma fazı ve diğer zararlı çökeltilerin oluşum sıcaklıkları ve bu sıcaklıklarda bekleme sürelerine dikkat etmek malzemenin korozyon dayanımını koruması için yararlı olacaktır.

Yüksek kromlu ( $>\% 20)$ paslanmaz çeliklerde; sigma fazı oluşumunun en hızlı olduğu sıcaklık aralıklarında $\left(800^{\circ} \mathrm{C}\right.$ ile $850^{\circ} \mathrm{C}$ ) sadece birkaç saat bulunma ile sigma fazı kolaylıkla ve daha hızlı bir şekilde meydana gelebilmektedir [11]. Dubleks paslanmaz çeliklerde; gerek kullanım gerekse imalat koşullarından dolayı meydana gelebilecek başta sigma olmak üzere zararlı metaller-arası bileşiklerin yapıda çözündürülüp giderilmesi için çözeltiye alma ve suda soğutma ısıl işlemi uygulanması fayda sağlayacaktır.

Araştırmacılar; 2205 dubleks paslanmaz çelikler ile ilgili yaptıkları çalışmalarda, $1120^{\circ} \mathrm{C}-1150^{\circ} \mathrm{C}$ sıcaklık aralığında uyguladıkları 1sıl işlemin mevcut sigma fazını tamamen giderdiğini belirlemişlerdir [12].

\section{Kaynaklar}

[1] J. Lippold and D. Kotecki: Welding Metallurgy and Weldability of Stainless Steels, Wiley Interscience Publications, New Jersey (2005)

[2] Gunn N. Robert: Duplex Stainless Steels, Microstructures, Properties and Applications, Abington Publishing, Cambridge, England (2003)

[3] ASM Handbook Vol.9, Metallography and microstructures of Stainless Steels and Maraging Steels,p.670-1656, USA, (2004)

[4] F.Tehovnik ve arkadaşları, Microstructure evolution in SAF
2507Superduplex Stainless Steel, Slovenia, (2011)

[5] ASTM A 923-08 'Standart Test Methods for Detecting Detrimental Intermetallic Phase in Duplex Stainless Steels, USA, (2008)

[6] ASTM E-562-11, Standard Test Method for Determining Volume Fraction by Systematic Manual Point Count, (2011)

[7] ASTM E 1245-03, Standard Practice for determining the Inclusion or Second Phase Constituent Content of Metals by Automatic Image Analysis (Re-approved 2008)

[8] Pierre R. Roberge, Handbook of Corrosion Engineering, Chapter 8, 734, Materials' Selection, McGrawHill Publications, (2000)

[9] Welding Brazing and Soldering, ASM Metals Handbook Vol.6. ASM International, USA, (1993)

[10] J.D.Fritz, Effects of metallurgical variables on the corrosion of stainless steels, Corrosion: Fundamentals, Testing and Protection, Vol. 13-A, ASM Handbook, ASM Int.,(2003)

[11] Shortsleeve F.J, and Nicholson M.E, Transformations in ferriticchromium steels between $595-815^{\circ} \mathrm{C}$, ASM,(1951)

[12] Kotecki, D.J, Heat treatment of duplex stainless steels, 68 (11), 431441, Welding Journal, (1989) 